\title{
THE ROLE OF BOREHOLE GEOPHYSICS IN IMPROVING THE GEOPHYSICAL IMAGING OF KIMBERLITES IN A SEDIMENTARY SETTING : ALBERTA, CANADA.
}

\author{
Richard Kellett, Ryan Zahynacz and Gilein Steensma \\ Komex International Ltd., Canada
}

\section{INTRODUCTION}

Since the late 1980's kimberlite exploration in Alberta has developed at a rapid pace. The potential of the Archean and Proterozoic crust, beneath the Western Canadian Sedimentary Basin, as a source of diamondiferous kimberlites was recognized almost immediately after the discovery of the Lac de Gras kimberlites in the Northwest Territories (Dufresne et al., 1996). To date over 40 kimberlite intrusions have been discovered in the sedimentary basins of Alberta and Saskatchewan (Figure 1). The most important finds from an economical perspective are the Fort a la Corne kimberlites in Saskatchewan and the Buffalo Head Hills field in northwest Alberta. The Mountain Lake Intrusion in western Alberta is another important discovery because of its location, its level of exposure, and the large quality of data available.

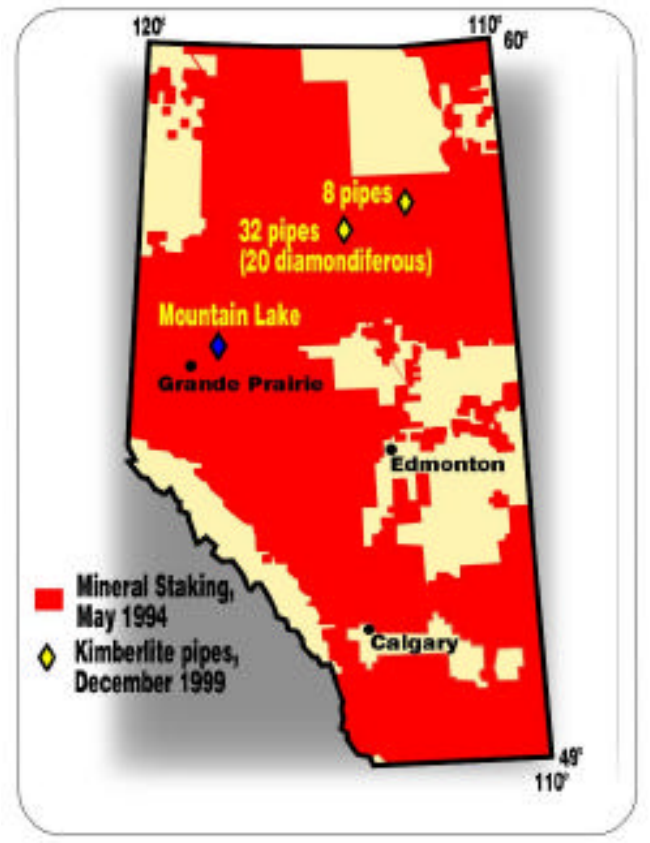

Figure 1 : Location of Alberta Kimberlites

Geophysical methods are an important component in kimberlite exploration on the shield and are even more important for exploration in a sedimentary basin setting. A wealth of geophysical data exists in Alberta and
Saskatchewan resulting from the long history of oil and gas exploration. These data have been used successfully to screen large areas of the prairies for possible kimberlite targets. These geophysical methods include airborne magnetics, seismic reflection, and land-based gravity surveys. A key component that ties the regional geophysical data to geology and more localized exploration is geophysical borehole logging.

Geophysical borehole logs are collected routinely by the oil and gas industry. Geophysical measurements of density, resistivity, natural gamma emissions, and sonic velocity are very useful for identifying kimberlites and interpreting geophysical data. We discuss the physical properties derived from the borehole logs from kimberlites in northern Alberta and use these to help interpret surface and airborne geophysical data from the Mountain Lake Intrusion.

\section{BOREHOLE GEOPHYSICS}

Between 1997 and 1999 Komex International Ltd. logged 36 boreholes in Alberta for numerous kimberlite exploration programs. The logging suites included natural gamma-ray spectrometry, magnetic susceptibility, inductive conductivity, temperature, and three-component magnetics. All holes were logged in two-inch PVC casing with no annular packing. Despite the wide variation in physical properties of kimberlite, even within a single pipe, borehole geophysical logs do effectively distinguish kimberlite from host rock. A summary of geophysical properties derived for the sampled kimberlites is given in Table $\mathbf{1 .}$

\section{NATURAL GAMMA}

Total natural gamma counts and uranium counts appear to be the only $\log s$ that are consistently diagnostic of kimberlite. Both total counts and uranium counts usually exceed background values by at least fifty per cent.

\section{TEMPERATURE}

Fluid temperatures rise by as much as $2^{\circ} \mathrm{C}$ within the top several metres of a kimberlite intrusion. These 
anomalous temperature gradients may be related to the elevated uranium concentrations or simply to fracturing and fluid influx into the borehole.

\section{Table 1: Geophysical properties}

$\begin{array}{lll}\text { Property Units } & \text { Kimberlite } & \text { Host } \\ \text { Gamma cps } & 100-120 & 50-80 \\ \text { Resistivity ohm.m } & 80-100 & 20-50 \\ \text { Conductivity } \mathrm{mS} / \mathrm{m} & 10-15 & 15-20 \\ \text { Susceptibility } \mathrm{mSI} & 10-20 & <10 \\ \text { Density } \mathrm{kg} / \mathrm{m}^{3} & 2200-2300 & <2000 \\ \text { Velocity } \mathrm{m} / \mathrm{s} & 2000-2200 & <1800\end{array}$

\section{RESISTIVITY}

Kimberlite resistivities, derived from Geonics EM39 conductivity logs, exceeded 80 ohm.m whereas overburden and host rock resistivities were commonly less than 50 ohm.m (Figure 2).

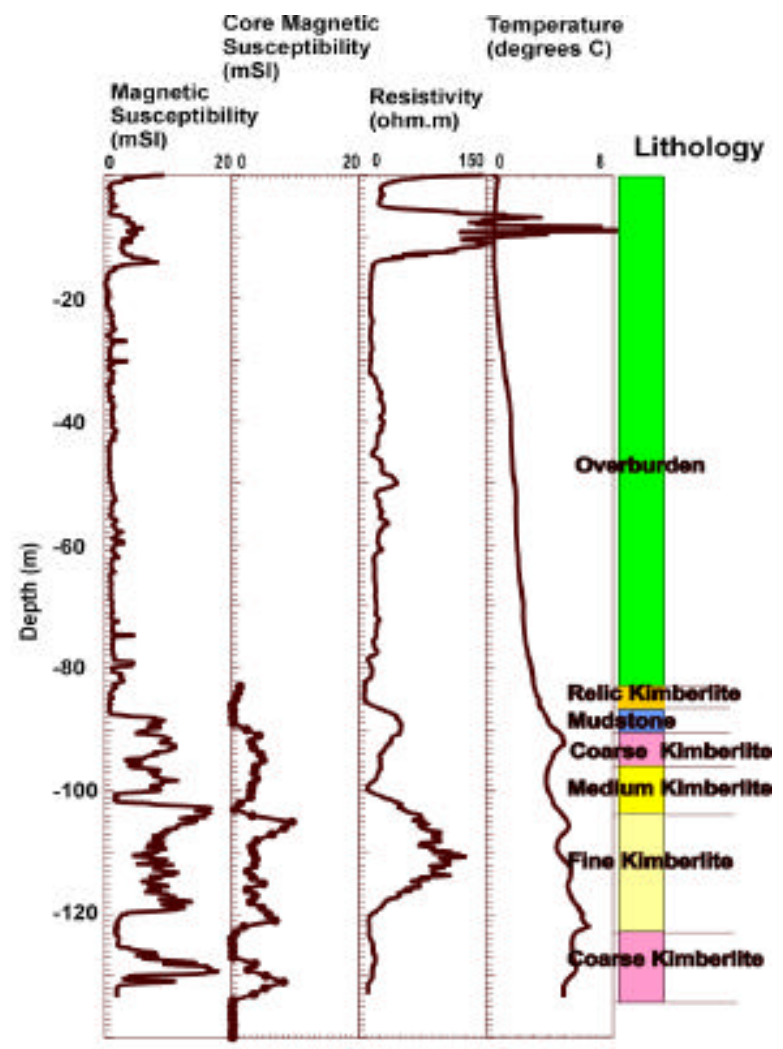

Figure 2 : Typical Geophysical Borehole Log of Kimberlite in a Sedimentary Host from Northern Alberta

\section{MAGNETIC PROPERTIES}

Kimberlite displays elevated magnetic susceptibilities with values ranging from 2 to $40 \mathrm{mSI}$ units, while background values are generally less than $2 \mathrm{mSI}$ units (Figure 2). Measurements of the magnetic susceptibility derived from geophysical logs have the advantage of being continuous from surface casing to the base of the hole. In particular magnetic properties can be derived for zones of poor core recovery such as the overburden and the critical top few metres of the kimberlite.

\section{DENSITY AND SONIC VELOCITY}

Density and velocity $\log$ s are collected by the oil and gas exploration industry but are rarely collected for mineral exploration. Density and sonic logs were collected by the Geological Survey of Canada as part of their investigation of the Mountain Lake Intrusion (Leckie et al., 1997). The fresh and weathered kimberlite is characterized by higher density than the surrounding tills, sandstones, and siltstones. The sonic velocity of the weathered kimberlite and tuffs is highly variable. Massive kimberlite has a higher velocity than the surrounding sediments.

\section{GEOPHYSICAL INTERPRET ATION OF THE LOGS}

The magnetic and electrical resistivity values derived from the logging study can be used to model the response of kimberlites to both ground and airborne geophysical surveys. Sonic velocity and density logs are crucial for constructing synthetic seismograms used in the interpretation of seismic reflection data. Density data derived from $\log s$ are used in the modelling of gravity anomalies over the kimberlites. In addition to the physical property logs discussed above, several geophysical tools can be used to explore for targets not intersected by the borehole. Vector magnetics can be processed to yield the direction and distance to a magnetic body located off-hole. Seismic proximity surveys can be used to find nearby kimberlite plugs in a manner similar to that used to image salt intrusions. 


\section{MOUNTAIN LAKE INTRUSION}

The Mountain Lake volcanic rocks outcrop on a prominent oval shaped hill $50 \mathrm{~km}$ northwest of Valleyview, Alberta (Figure 1). Since 1989, several mining companies (Monopros Ltd., Lucero Resource Corp., and New Claymore Resources Ltd.) have undertaken exploration of the kimberlite. This exploration included till sampling, drilling, and geophysical surveys. In 1995 the Geological Survey of Canada, in association with the Alberta Geological Survey, initiated a program to drill two holes to investigate the volcanics and intrusives. In addition to the drilling, the project included three geophysical components;

- An airborne magnetic survey was flown over the intrusion;

- Borehole geophysical logs were collected in the two exploration wells;

- A regional seismic line, that crossed the northern part of the anomaly, was acquired from the oil industry.

The results of the drilling and geophysical surveys are presented in GSC Open File Report 3441 (Leckie et al., 1997). Since the publication of that report many other geophysical datasets have been collected over the intrusion. These additional datasets include airborne electromagnetic (VLF and GEOTEM), ground electromagnetic (MaxMin), ground magnetic, gravity, resistivity, and seismic reflection surveys.

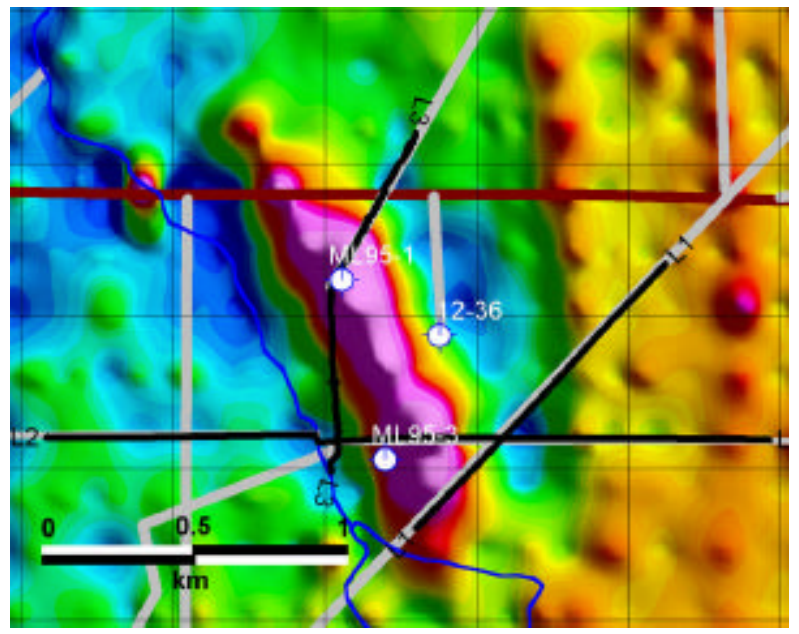

Figure 3 : Vertical Magnetic Gradient Map

\section{MAGNETIC SIGNATURE}

Airborne magnetic data are available from three surveys (Leckie et al., 1997, Terraquest 1999, New Claymore 1999). All three surveys have similar survey parameters (line-spacing $200 \mathrm{~m}$, sensor elevation of 90 $-120 \mathrm{~m})$. A small total field anomaly $(\sim 10 \mathrm{nT})$ is observed over the intrusion after the removal of the regional trend. The vertical gradient of the field shows a well defined elongate anomaly striking northnorthwest with a width of $250 \mathrm{~m}$ and a strike-length of $1.5 \mathrm{~km}$ (Figure 3). The ground magnetic surveys are collected at a tighter line spacing $(100 \mathrm{~m})$ and show that the anomaly is divided into two distinct centers. Boreholes ML95-1 and ML95-3 were drilled into these two targets (Figure 3).

\section{RESISTIVITY SIGNATURE}

Resistivity information is available from four different geophysical surveys and three logs. An airborne magnetic survey in 1999 collected total field Very Low Frequency (VLF) data over a regional grid. The data are highly affected by drift and noise but a subtle anomaly is observed over the kimberlite (Terraquest, 1999). The airborne transient electromagnetic survey (GEOTEM) over the target showed a similar pattern of highly variable conductivity across the area (New Claymore Resources, 1999). The GEOTEM data are responding to the tills and bedrock. Horizontal loop electromagnetic surveys (MaxMin) were collected on tight grids on the ground. The weathered kimberlite is imaged as a conductive body surrounded by moderately resistive sandstones.

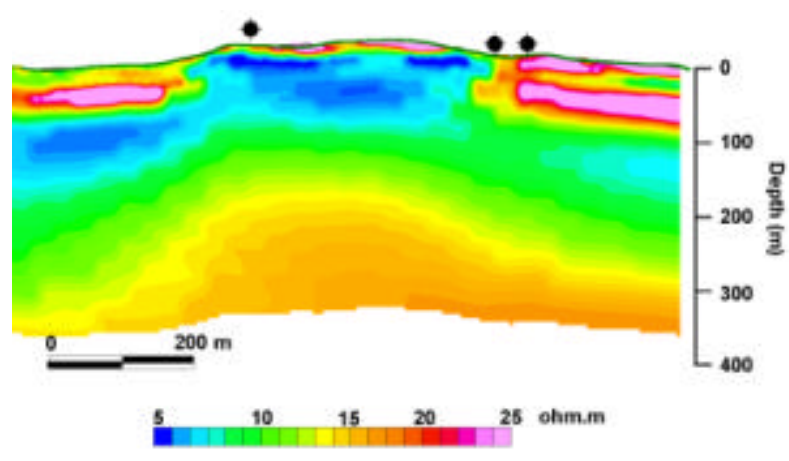

Figure 4 : Resistivity Cross-section Line L2

Komex collected three lines of deep resistivity across the intrusion in 2002 (see Figure 3 for locations). Line 1 and Line 3 extend to a depth of $200 \mathrm{~m}$. Line L2 extends to $400 \mathrm{~m}$ depth. Figure 4 shows a detailed section from the centre of line L2. The intrusion is 
clearly imaged as a conductive zone, extending to a depth of $75 \mathrm{~m}$ under the hill. There is a thin veneer of resistive cover over the hill. On the flat portion of the line the overburden is more than $30 \mathrm{~m}$ thick and has a resistivity of 30 ohm.m. A resistive bedrock unit extends to a depth of $90 \mathrm{~m}$. A major contact is seen across the entire section at a depth of $280 \mathrm{~m}$. A resistive anomaly under the topographical high may be evidence of a diatreme at a depth of $250 \mathrm{~m}$.

Resistivity $\log$ s are available from boreholes ML95-3, ML95-1 and well 12-36 (Figure 3). The weathered kimberlite intersected by ML95- 1 and 3 shows a wide range of resistivities but generally the tuffs are less than $50 \mathrm{ohm} . \mathrm{m}$. Well 12-36 was cased to a depth of $300 \mathrm{~m}$ so resistivity data from this well can only be used to constrain the resistivities of the deeper sedimentary units.

\section{GRAVITY SIGNATURE}

De Beers Canada Exploration collected a dense grid of gravity data over the intrusion. The gravity measurements were made at a station spacing of $50 \mathrm{~m}$ along lines spaced $100 \mathrm{~m}$ apart. A Bouguer anomaly of $0.3 \mathrm{mGal}$ was observed over the intrusion. The extent of the gravity anomaly is very similar to the magnetic anomaly. A simple half-width interpretation of the gravity data suggests a source depth of approximately $250 \mathrm{~m}$. Detailed modelling has been performed by Komex using geometries constrained by the resistivity and seismic data, and densities derived from the borehole logs.

\section{SEISMIC SignATURE}

A total of six seismic lines have been collected over the intrusion. Five of the lines were collected by oil and gas exploration companies and were designed to image deeper sedimentary targets. Three of these lines have been obtained by Komex and are included in the interpretation of the geometry of the kimberlite (Komex 2003). The regional lines show a zone of highly irregular reflectivity across the intrusion. Line PK4 shows a strong diffraction pattern with the apex located over the centre of the magnetic anomaly. This diffraction pattern is probably the result of energy scattered from the kimberlite pipe back into the section. Obvious pull-up is seen in the reflections at depth below this point indicating that there are significant contributions from out-of-plane reflectors.

Another oil industry seismic line collected over the centre of the intrusion was processed to minimize the complexity resulting from near surface structures and can only be used to constrain the deeper flat lying sedimentary units.

Komex collected a high-resolution seismic reflection line across the intrusion in 2003. The line was shot using a $4 \mathrm{~m}$ geophone spacing, 240 channels, and an 8 $\mathrm{m}$ shot point interval (Figure 5). The section shows a strong reflection from the Dunvegan and Paddy Formations at depth. These units can be correlated with other seismic lines and the well log from 12-36. Under the hill, which marks the centre of the intrusion, the shallow reflections are disrupted. An approximately trapezoidal zone of complex reflections coincides with the topographical expression of the intrusion at surface, and narrows with depth. (Figure 5).

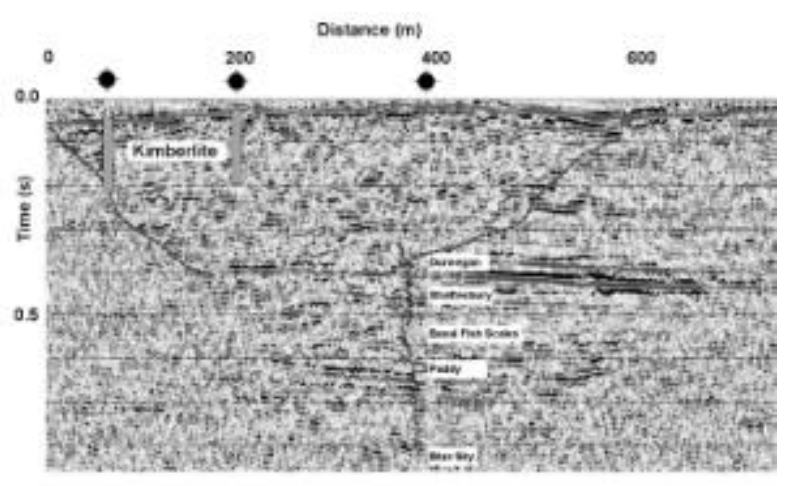

Figure 5 : Seismic Reflection Section

\section{SUMMARY}

A large amount of geophysical data has been acquired over kimberlites in the Western Canadian Sedimentary Basin in Alberta and Saskatchewan. Komex has compiled data from over 36 well logs in northern Alberta, and 10 years of exploration of the Mountain Lake Intrusion. The geophysical properties derived from the $\log$ s are critical to validate interpretations of the airborne and ground geophysical data.

The borehole geophysical information collected specifically for kimberlite exploration together with the wide range of borehole, ground and airborne geophysical measurements made at the Mountain Lake Intrusion provide an excellent database for the general characterization of kimberlitic intrusions. The tie to both regional and high-resolution seismic reflection data provides support for the use of seismic datasets as a important tools for kimberlite exploration. 


\section{ACKNOWLEDGMENTS}

The authors would like to thank the following groups for supporting the project and contributing data, equipment, and support: New Claymore Resources, De Beers Canada Exploration, Sigma Exploration, GEDCO, University of Alberta, Imperial Oil Resources, Devon Canada, Anadarko Canada, Ashton Mining of Canada, Kennecott Canada, and the Alberta Geological Survey.

\section{REFERENCES}

Dufresne, M.B., Eccles D.R., McKinstry, B., Schmitt, D.R., Fenton, M.M., Pawlowicz and W.A.D Edwards, 1996. The Diamond Potential of Alberta. Alberta Geological Survey Bulletin No. 63

Komex 2003. The Geophysical Signature of the Mountain Lake Intrusion. Alberta Geological Survey, Special Report in prep.

Leckie, D. A., Kjarsgaard, B., et al., 1997. Geology of a Late Cretaceous Possible Kimberlite at Mountain Lake Alberta - Chemistry, Petrology, Indicator Minerals, Aeromagnetic Signature, Age, Stratigraphic Position and Setting. GSC Open File Report 3441.

New Claymore Resources Ltd., 1999. Assessment Report Fahler Prospect.

Terraquest Ltd., 1999. High Resolution Aeromagnetic Survey, Kimberly Prospect, Mountain Lake, Alberta. Report prepared for New Claymore Resources LTD.

Contact: RL Kellett, Komex International Ltd, Suite 100, 4500-16 ${ }^{\text {th }}$ Ave. NW, Calgary, AB, Canada, T3B 0M6, E-mail: rkellett@calgary.komex.com 